\title{
Sistem Pendukung Keputusan Pemilihan Restoran (Nom.Philia) di Kota Palembang
}

\author{
Maria Bellaniar Ismiati ${ }^{1}$, Latius Hermawan ${ }^{2}$, Violentina Wijaya ${ }^{3}$ \\ 1,3 Sistem Informasi, Universitas Katolik Musi Charitas, JL. Bangau No.60 Palembang \\ ${ }^{2}$ Informatika, Universitas Katolik Musi Charitas, JL. Bangau No.60 Palembang
}

\begin{tabular}{l}
\hline Info Artikel \\
\hline Riwayat Artikel \\
Diterima: $18-11-2020$ \\
Direvisi: $27-11-2020$ \\
Disetujui: $07-12-2020$
\end{tabular}

$\underline{\text { Kata Kunci }}$

Kuliner;

Sistem Pendukung

Keputusan;

Restoran;

Corresponding Author

Maria Bellaniar Ismiati, Tel. +62 81802735717

bella@ukmc.ac.id

\begin{abstract}
ABSTRAK
Dunia kuliner semakin berkembang dari segi rasa, variasi makanan, kuantitas dan kualitas, bahkan dari sisi teknologinya. Banyak kota-kota besar yang kulinernya semakin berkembang, salah satunya adalah kota Palembang yang memiliki banyak referensi kuliner yang disuguhkan di dalam banyak restoran/rumah makan. Akan tetapi masih banyak masyarakat kota Palembang yang masih belum banyak tahu mengenai restoran apa saja yang ada di Palembang. Selain faktor ketidaktahuan, seringnya masyarakat juga bingung untuk menentukan bahwa mereka akan makan dimana saat ini. Hal tersebut juga dikarenakan adanya faktor kebosanan untuk makan di restoran yang itu-itu saja dan seringnya suasana hati yang berubah-ubah dari masyarakat itu sendiri. Berdasarkan permasalahan tersebut, peneliti membuat suatu Sistem Pendukung Keputusan Pemilihan Restoran di kota Palembang. Dalam pengembangan software-nya, peneliti menggunakan model waterfall yang dimulai dari communication, planning, modelling, construction, dan deployment serta Bahasa pemrograman yang digunakan adalah Visual Basic. Hasil penelitian ini adalah telah terbangunnya suatu sistem pendukung keputusan pemilihan restoran di kota Palembang dengan menampilkan daftar pertanyaan berdasarkan kriteria sebagai berikut menu makanan, harga, fasilitas, suasana, daya tampung, dan khas makanan. Selain itu juga telah tampil daftar rekomendasi restoran yang sesuai keinginan user dengan dilengkapi informasi berupa lokasi, jam operasional, fasilitas, dan alamat website.
\end{abstract}

\section{PENDAHULUAN}

Seiring dengan kemajuan zaman, kemajuan teknologi informasi juga semakin hari semakin berkembang. Perkembangan teknologi informasi ini, berdampak pada berbagai bidang kehidupan masyarakat baik dari segi sosial, ekonomi, pendidikan, pembangunan, pariwisata maupun kuliner. Penelitian ini akan mengambil objek di bidang kuliner yang merupakan salah satu bidang kehidupan yang disukai oleh semua masyarakat di berbagai kota. Salah satunya adalah kota Palembang yang merupakan salah satu kota yang juga memiliki banyak referensi kuliner yang disuguhkan di dalam banyak restoran/rumah makan yang selalu bertambah setiap tahunnya.

Dengan semakin bertambah banyaknya restoran, maka banyak pula pilihan restoran yang tersebar di berbagai lokasi di kota Palembang. Restoran tersebut terbagi menjadi beberapa jenis bagian, yaitu biasanya kelas restoran, harga makanan, fasilitas, dan layanan. Oleh karena luasnya wilayah di kota Palembang ini, maka terdapat restoran- restoran yang belum diketahui, baik oleh masyarakat Palembang sendiri maupun para pendatang yang berkunjung ke kota 
Palembang. Hal tersebut membuat konsumen yang terdiri dari masyarakat Kota Palembang maupun pendatang yang berasal dari luar kota Palembang, masih merasa bingung dan membutuhkan informasi lebih mengenai restoran-restoran yang ada di kota Palembang. Selain faktor ketidaktahuan mengenai restoran yang ada di kota Palembang, seringnya masyarakat juga bingung untuk menentukan bahwa mereka akan makan dimana saat ini. Hal tersebut juga dikarenakan adanya faktor kebosanan untuk makan di restoran yang itu-itu saja dan seringnya suasana hati yang berubah-ubah dari masyarakat itu sendiri. Alasan-alasan tersebut didapatkan dari hasil wawancara dengan beberapa responden. Berdasarkan permasalahan tersebut, peneliti membuat suatu Sistem Pendukung Keputusan Pemilihan Restoran di Kota Palembang.

Setelah memberikan penjelasan mengenai permasalahan dan aplikasi yang dibuat, perlu diketahui juga teori-teori pendukung penelitian ini, yaitu teori mengenai restoran, sistem pendukung keputusan, model pengembangan software (Waterfall), pengujian sistem (blackbox), dan tools yang digunakan dalam penelitian ini. Secara teori, restoran menurut [1] adalah suatu tempat atau bangunan yang diorganisasi secara komersial, yang menyelenggarakan pelayanan dengan baik kepada semua tamunya baik berupa makan maupun minum. Sedangkan menurut [2] restoran berarti rumah makan. Selanjutnya, Sistem Pendukung Keputusan menurut [3] adalah sistem yang interaktif, membantu pengambilan keputusan melalui penggunaan data dan model-model keputusan untuk memcahkan masalah-masalah yang sifatnya semi terstruktur dan tidak struktur.

Sistem Pendukung Keputusan yang dibuat dalam penelitian ini untuk memberikan rekomendasi pemilihan restoran berdasarkan informasi yang didapatkan dari jawaban pengguna / user. Sistem ini memberikan pertanyaan-pertanyaan berdasarkan beberapa kriteria, yaitu menu makanan, harga, fasilitas, suasana, daya tampung, dan khas makanan. Selain itu pula, jawaban yang diberikan oleh user adalah yang sesuai dengan keinginan user itu sendiri sehingga saat daftar rekomendasi restoran tampil, maka restoran-restoran tersebut adalah tempat yang akan dikunjungi sesuai dengan keinginan user sendiri. Yang dimaksud sesuai keinginan user adalah saat user menjawab Ya tau Tidak dari pertanyaan-pertanyaan yang ditampilkan di aplikasi Nom.Philia ini. Contohnya ada pertanyaan: apakah kamu mau makanan pedas? Dan bila user menjawab Ya, berarti saat ini user sedang ingin makan makanan pedas di salah satu restoran di Palembang.

Sistem ini memberikan output berupa pilihan restoran dengan menggunakan bahasa pemrograman Visual Basic. Daftar rekomendasi restoran yang dibuat ada 3, yaitu restoran Indonesia, restoran Fast food, dan restoran untuk nongkrong. Dalam masing-masing rekomendasi restoran tersebut, diberikan pula 5 nama restoran untuk masing-masing jenis restorannya. Selain nama restoran, diberikan pula lokasi, jam perasional, fasilitas, dan alamat website-nya. Setelah daftar rekomendasi restoran muncul, maka keputusan terakhir tetap akan diberikan kepada user untuk memilih restoran yang mana yang akan dikunjungi. Begitulah sebenarnya proses kerja dari sistem pendukung keputusan dimana sistem akan memberikan rekomendasi dan keputusan akhir tetap ada di tangan user sendiri. Dalam mendukung pembuatan Sistem Pendukung Keputusan ini, diperlukan suatu model dalam mengembangkan software-nya.

Dalam pengembangan software-nya, peneliti menggunakan metode Waterfall. Menurut [4] model waterfall adalah model klasik yang bersifat sistematis, berurutan dalam membangun software. Model ini sering dianggap kuno, tetapi merupakan model yang paling banyak dipakai dalam Software Engineering (SE). Model ini melakukan pendekatan secara sistematis dan berurutan. Disebut dengan waterfall karena tahap demi tahap yang dilalui harus menunggu selesainya tahap sebelumnya dan berjalan berurutan. Setelah dilakukan tahapan untuk model pengembangan software-nya, diperlukan pula suatu pengujian kepada system yang dibuat agar dapat dilihat sesuai atau tidaknya denga napa yang dilakukan dan diharapkan oleh pengguna dan sistem itu sendiri.

Untuk pengujian yang dilakukan dalam penelitian ini adalah pengujian blackbox. Menurut [5], black box testing adalah suatu metode pengujian dimana tester hanya fokus pada 
apa yang seharusnya dilakukan oleh sistem. Sebuah tes dapat dikatakan berhasil ketika sebuah sistem dapat memproses data dan hasil yang ada sesuai dengan apa yang diharapkan. Selain itu, untuk pengujian kepada responden, digunakan kuisioner yang disebarkan melalui Google Form kepada 30 orang (masyarakat umum). Hasilnya dihitung menggunakan statistika deskriptif yang berupa persentase dari masing-masing pertanyaan yang dijawab oleh responden itu sendiri mengenai pengalamannya dalam menggunakan SPK Nom.philia. Dalam pembuatan SPK Nom.philia ini menggunakan suatu tools yaitu Visual Basic yang merupakan bahasa pemrograman generasi ke tiga dari Microsoft dengan IDE (Integrated Development Environment) atau pemrograman pengembangan terpadu, visual basic dibuat dan dirancang untuk mudah digunakan baik oleh programmer pemula sekalipun. Pengertian teori visual basic tersebut menurut [6]. Selain penjelasan mengenai teori-teori yang mendukung, dijabarkan pula penjelasan mengenai penelitian terdahulu yang berkaitan dengan penelitian ini yaitu dari Hamdani dan Fuspita.

Pada penelitian terdahulu, [7] telah membuat penelitian dengan judul Sistem Pendukung Keputusan Wisata Kuliner dengan Visualisasi Geografi di Yogyakarta. Sistem pendukung keputusan yang dibuat mengunakan perpaduan antara Sistem Pendukung Keputusan dan Sistem Informasi dan Geografis dan membahas tentang rekomendasi wisata kuliner di Yogyakarta. Selain itu, [8] juga membuat Sistem Pendukung Keputusan Pemilihan Restoran di kota Bengkulu dengan metode simple additive weighting berbasis sistem operasi android. Pemilihan restoran berdasarkan beberapa kriteria, yaitu menu makanan, harga, khas, fasilitas, suasana, jam buka, dan juga daya. Berdasarkan dua penelitian di atas, yaitu mengenai pembuatan suatu Sistem Pendukung Keputusan, maka penelitian ini juga membuat suatu Sistem Pendukung Keputusan Pemilihan Restoran (Nom.Philia) di kota Palembang. Dari kedua penelitian terdahulu, SPK yang dibuat berbasis Sistem Informasi Geografis dan Android dimana penelitian ini juga akan berbasis Android tetapi dengan menggunakan beberapa kriteria yang berbeda dan telah disesuaikan dengan situasi dan kondisi yang ada. Situasi dan kondisi yang ada di kota Palembang juga dilihat dari jenis-jenis restoran yang akan ditampilkan di aplikasi Nom.Philia ini.

\section{METODE}

Metode penelitian yang mendukung penelitian ini dimulai dari analisa kebutuhan, perancangan antar muka, perancangan sistem, desain dan implementasi, pengujian sistem, dan penyusunan laporan. Subjek penelitian yang digunakan adalah masyarakat awam yang biasanya kebingungan untuk memilih restoran. Proses pembuatan sistem pendukung keputusannya, dilakukan berdasarkan urutan flowchart dan desain antar muka pada Gambar 1

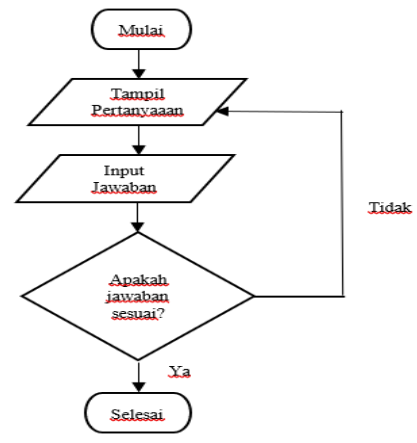

Gambar 1. Flowchart Sistem

Proses detail sistem berdasarkan flowchart di atas adalah sebagai berikut:

a. Urutan proses dimulai dari user membuka aplikasi Nom.Philia

b. Kemudian user akan melihat tampilan pertanyaan-pertanyaan yang harus dijawab oleh user agar didapatkan hasil restoran yang sesuai dengan keinginan user 
c. Setelah itu, user harus meng-input jawaban dengan melakukan klik di salah satu jawaban Ya atau Tidak pada aplikasi tersebut.

d. Setelah semua jawaban selesai diisi, maka user akan mendapatkan rekomendasi restoran yang sesuai dengan keinginan user tersebut. Rekomendasinya berupa nama restoran, lokasinya, jam operasional restoran, dan alamat websitenya.

e. Setelah selesai mendapatkan rekomendasi restoran, maka user dalam keluar dari aplikasi Nom.philia

Desain antarmuka disini akan dijelaskan mengenai menu-menu dan fungsionalitasnya dari awal hingga akhir menu aplikasi Nom.philia tersebut. Penjabarannya sebagai berikut:

a. Tampilan awal berupa Logo Nom.philia serta tagline berupa: Mau makan dimana hari ini? Dibawahnya diberikan tombol Ready, Set, Go untuk dapat masuk ke halaman berikutnya

b. Halaman selanjutnya diberikan tampilan daftar pertanyan yang mengarah ke keinginan user untuk memilih restoran apa hari ini. Di samping pertanyaan, diberikan radio button yang diberi nama Ya dan Tidak sehingga user hanya dapat memilih salah satu dari kedua pilihan tersebut. Selain itu diberikan pula tombol I'm done dan I'm quit agar ketika user telah selesai memilih jawabannya maka user dapat berpindah ke halaman berikutnya. Apabila user tidak mengisi semua jawaban, maka akan muncul message box agar user dapat melengkapi semua jawaban di halaman ini.

c. Apabila semua jawaban yang sesuai dengan keinginan user telah selesai dijawab, maka akan muncul rekomendasi restoran-restoran yang cocok dengan keinginan user itu sendiri berupa nama restoran, lokasi, jam operasional, fasilitas, dan alamat websitenya. Selain itu, diberikan pula tombol Again, again dan I'm quit agar user dapat memilih satu dari kedua pilihan tersebut.

\section{HASIL DAN PEMBAHASAN}

Hasil dan pembahasan akan dijabarkan dalam bentuk gambar atau tampilan antar muka sistem pendukung keputusan pemilihan restoran Nom.philia di Kota Palembang ini.

a. Tampilan awal Nom.philia

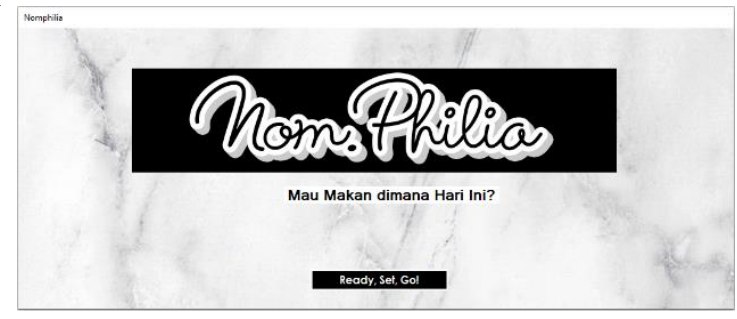

Gambar 2. Tampilan Awal Aplikasi Nom.philia

Pada tampilan awal ini, user akan melihat logo, tagline, dan tombol Ready, Set, Go! agar user dapat langsung masuk ke menu utama di aplikasi ini. User hanya tinggal melakukan klik pada tombol tersebut agar dapat segera menjawab pertanyaan-pertanyaan yang akan merekomendasikan restoran mana yang sesuai dengan keinginan user.

b. Tampilan Daftar Pertanyaan

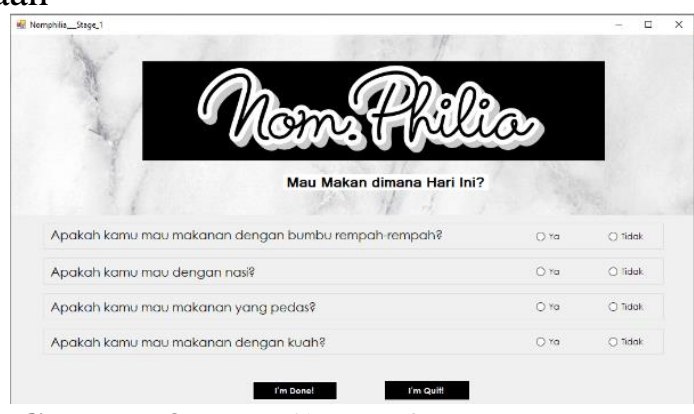

Gambar 3. Tampilan Daftar Pertanyaan (1) 

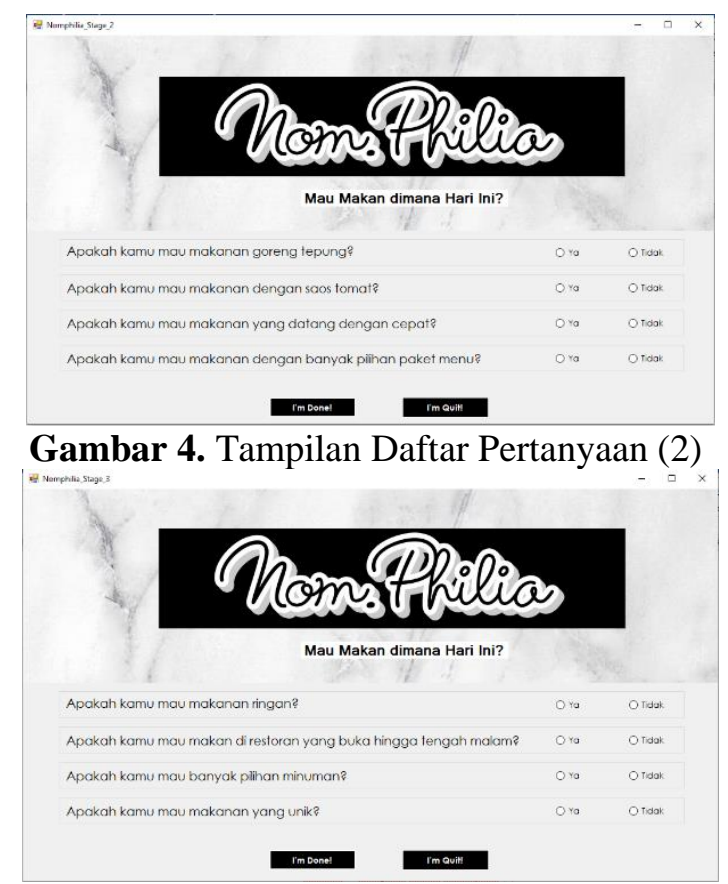

Gambar 5. Tampilan Daftar Pertanyaan (3)

Pada halaman ini, ditampilkan beberapa pertanyaan yang berkaitan dengan rekomendasi pemilihan restoran yang sekarang sedang diinginkan oleh user. Selanjutnya user hanya tinggal memilih salah satu jawaban antara Ya dan Tidak yang sesuai dengan keinginan user saat ini. Setelah user selesai memilih jawaban-jawaban yang sesuai, maka user tinggal melakukan klik tombol I'm Done! Agar dapat melihat hasil yang ditampilkan oleh sistem Nom.philia ini.

c. Tampilan Rekomendasi Restoran

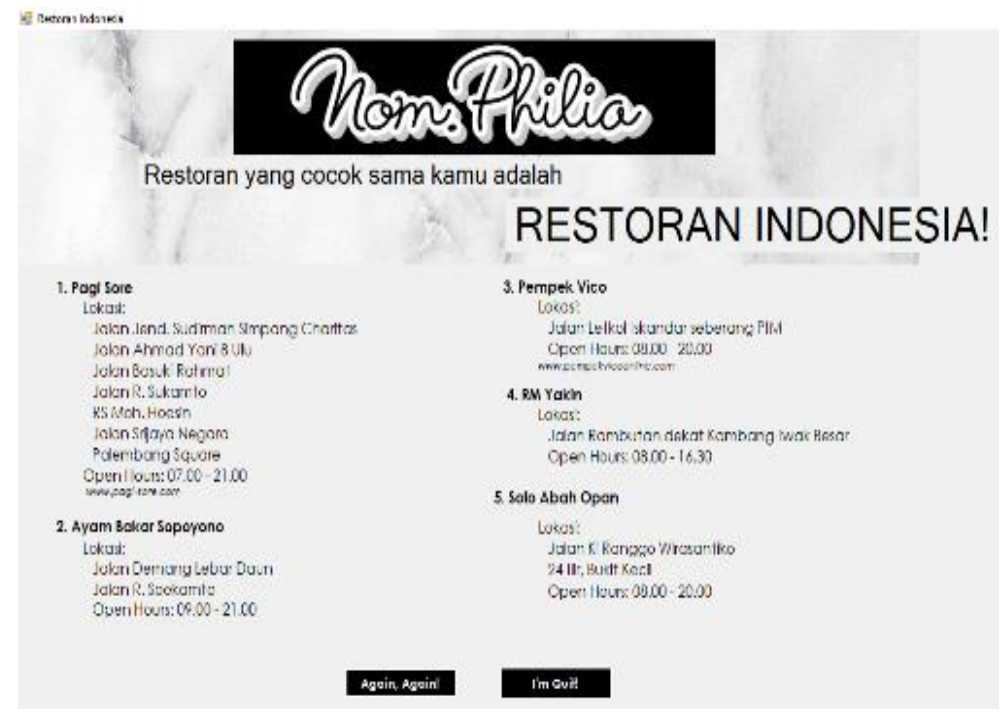

Gambar 6. Tampilan Rekomendasi Restoran

Pada halaman ini, user telah mendapatkan rekomendasi berdasarkan keinginan user melalui jawaban-jawaban dari pertanyaan yang telah dijawab oleh user tersebut. Tampilan di halaman ini adalah jenis Restoran (Indonesia, Fast Food, dan Nongkrong), Nama restoran, Lokasi, Alamat website.

d. Tampilan Message Box

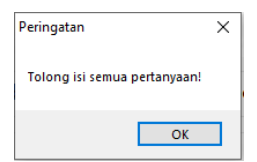

Gambar 7. Tampilan Message Box (1) 


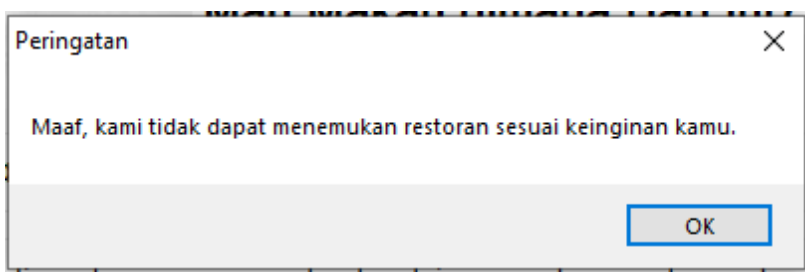

Gambar 8. Tampilan Message Box (2)

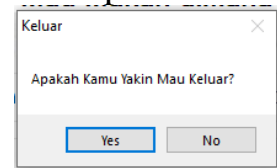

Gambar 9. Tampilan Message Box (3)

Pada halaman ini ditampilkan 3 buah message box yang muncul apabila user belum memilih semua pertanyaan dengan Ya atau Tidak (Gambar 7) dan apabila user menjawab pertanyaan dengan jawaban yang tidak sesuai dengan rule yang telah ditetapkan oleh peneliti (Gambar 8). Selanjutnya apabila user sudah selesai mencari rekomendasi restoran dan akan keluar dari sistem, maka akan muncul message box seperti pada Gambar 9.

e. Pengujian Blackbox

Pada Tabel 1 diberikan rincian pengujian blackbox yang dilakukan di sistem pendukung keputusan Nom.philia.

Tabel 1. Tabel Pengujian Blackbox

\begin{tabular}{|c|c|c|c|c|c|}
\hline No & Fitur & $\begin{array}{l}\text { Skenario } \\
\text { Pengujian }\end{array}$ & $\begin{array}{l}\text { Hasil yang } \\
\text { Diharapkan }\end{array}$ & Hasil Pengujian & Kesimpulan \\
\hline 1 & $\begin{array}{l}\text { Tombol } \\
\text { Ready, } \\
\text { Set, Go! } \\
\text { Di } \\
\text { halaman } \\
\text { awal }\end{array}$ & $\begin{array}{l}\text { User } \\
\text { melakukan } \\
\text { klik di tombol } \\
\text { tersebut }\end{array}$ & $\begin{array}{l}\text { Sistem } \\
\text { menerima } \\
\text { akses dan akan } \\
\text { menampilkan } \\
\text { halaman daftar } \\
\text { pertanyaan }\end{array}$ & 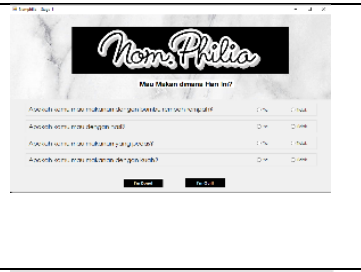 & Valid \\
\hline 2 & $\begin{array}{l}\text { Radio } \\
\text { button } \\
\text { jawaban } \\
\text { Ya dan } \\
\text { Tidak }\end{array}$ & $\begin{array}{l}\text { User } \\
\text { melakukan } \\
\text { klik di salah } \\
\text { satu tombol } \\
\text { tersebut } \\
\text { (sesuai } \\
\text { jawaban } \\
\text { responden) }\end{array}$ & $\begin{array}{l}\text { Sistem } \\
\text { menerima } \\
\text { akses dan } \\
\text { menampilkan } \\
\text { titik hitam } \\
\text { pada salah satu } \\
\text { jawaban }\end{array}$ & $\begin{array}{ll}\text { O ya } & \text { O Tidak } \\
\text { O ya } & \text { O ridak } \\
\text { O ra } & \text { O ridak } \\
\text { O ra } & \text { O ridak }\end{array}$ & Valid \\
\hline 3 & $\begin{array}{l}\text { Tombol } \\
\text { I'm } \\
\text { Done! }\end{array}$ & $\begin{array}{l}\text { User } \\
\text { melakukan } \\
\text { klik di tombol } \\
\text { tersebut }\end{array}$ & $\begin{array}{l}\text { Sistem } \\
\text { menerima } \\
\text { akses dan } \\
\text { apabila telah } \\
\text { sesuai maka } \\
\text { akan } \\
\text { menampilkan } \\
\text { daftar } \\
\text { rekomendasi } \\
\text { restoran }\end{array}$ & 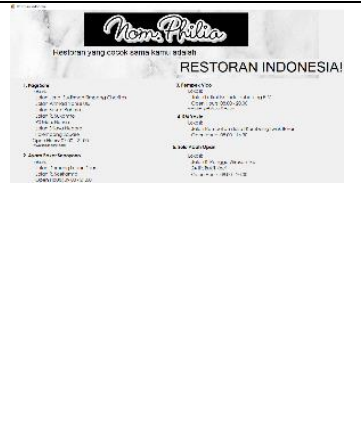 & Valid \\
\hline 4 & $\begin{array}{l}\text { Tombol } \\
\text { Again, } \\
\text { again! }\end{array}$ & $\begin{array}{l}\text { User } \\
\text { melakukan } \\
\text { klik di tombol } \\
\text { tersebut }\end{array}$ & $\begin{array}{l}\text { Sistem } \\
\text { menerima } \\
\text { akses dan akan } \\
\text { menampilkan } \\
\text { halaman awal } \\
\text { Nom.philia }\end{array}$ & 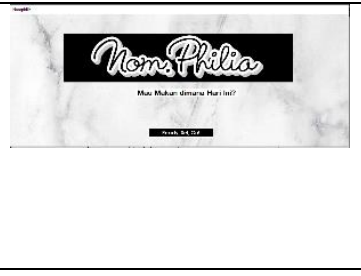 & Valid \\
\hline
\end{tabular}

f. Pengujian kepada user

User yang dijadikan objek penelitian / responden sebanyak 30 orang, yang terdiri dari masyarakat umum. Kuisioner disebarkan dalam bentuk Google Form dan hasil dari 
jawaban responden ditampilkan dalam bentuk Tabel. Hasilnya berupa statistika deskriptif, yaitu dalam bentuk persentase. Sebelum membahas mengenai diagram pie, berikut diberikan daftar pertanyaan yang diberikan kepada responden mengenai pengalamannya saat sudah menggunakan system Nom.philia ini.

Tabel 2. Daftar Pertanyaan Kuisioner Pengguna

\begin{tabular}{|c|l|c|c|}
\hline No & \multicolumn{1}{|c|}{ Pertanyaan } & Ya & Tidak \\
\hline 1 & Apakah Nom.philia ini mudah digunakan? & & \\
\hline 2 & Apakah Nom.philia ini mempunyai tampilan yang user friendly? & & \\
\hline 3 & $\begin{array}{l}\text { Apakah Nom.philia ini dapat memberikan rekomendasi yang sesuai } \\
\text { dengan harapan user dalam memilih restoran? }\end{array}$ & & \\
\hline 4 & $\begin{array}{l}\text { Apakah Nom.philia dapat membantu user saat kebingungan akan } \\
\text { makan dimana hari ini? }\end{array}$ & $\begin{array}{l}\text { Apakah Nom.philia merupakan suatu aplikasi yang sederhana dan } \\
\text { berguna bagi user? }\end{array}$ & \\
\hline
\end{tabular}

Hasil pengujian kepada 30 responden ditampilkan dalam bentuk Tabel dengan jumlah total dan persentase dari masing-masing pertanyaan yang diberikan di kuisioner.

Tabel 3. Jawaban Hasil Pengujian 30 Responden

\begin{tabular}{|c|c|c|c|c|c|c|c|c|c|c|}
\hline \multirow{3}{*}{ Responden } & \multicolumn{10}{|c|}{ Pertanyaan } \\
\hline & \multicolumn{2}{|c|}{$\begin{array}{c}\text { Apakah } \\
\text { Nom.philia } \\
\text { ini mudah } \\
\text { digunakan? }\end{array}$} & \multicolumn{2}{|c|}{$\begin{array}{c}\text { Apakah } \\
\text { Nom.philia ini } \\
\text { mempunyai } \\
\text { tampilan yang } \\
\text { user friendly? }\end{array}$} & \multicolumn{2}{|c|}{$\begin{array}{c}\text { Apakah } \\
\text { Nom.philia } \\
\text { ini dapat } \\
\text { memberikan } \\
\text { rekomendasi } \\
\text { yang sesuai } \\
\text { dengan } \\
\text { harapan } \text { user } \\
\text { dalam } \\
\text { memilih } \\
\text { restoran? }\end{array}$} & \multicolumn{2}{|c|}{$\begin{array}{c}\text { Apakah } \\
\text { Nom.philia } \\
\text { dapat } \\
\text { membantu } \\
\text { user saat } \\
\text { kebingungan } \\
\text { akan makan } \\
\text { dimana hari } \\
\text { ini? }\end{array}$} & \multicolumn{2}{|c|}{$\begin{array}{c}\text { Apakah } \\
\text { Nom.philia } \\
\text { merupakan } \\
\text { suatu aplikasi } \\
\text { yang } \\
\text { sederhana dan } \\
\text { berguna bagi } \\
\text { user? }\end{array}$} \\
\hline & $\mathrm{Ya}$ & Tidak & $\mathrm{Ya}$ & Tidak & $\mathrm{Ya}$ & Tidak & $\mathrm{Ya}$ & Tidak & $\mathrm{Ya}$ & Tidak \\
\hline 1 & $\sqrt{ }$ & & $\sqrt{ }$ & & $\sqrt{ }$ & & $\sqrt{ }$ & & $\sqrt{ }$ & \\
\hline 2 & $\sqrt{ }$ & & $\sqrt{ }$ & & & $\sqrt{ }$ & $\sqrt{ }$ & & $\sqrt{ }$ & \\
\hline 3 & $\sqrt{ }$ & & $\sqrt{ }$ & & $\sqrt{ }$ & & $\sqrt{ }$ & & $\sqrt{ }$ & \\
\hline 4 & $\sqrt{ }$ & & $\sqrt{ }$ & & $\sqrt{ }$ & & $\sqrt{ }$ & & $\sqrt{ }$ & \\
\hline 5 & $\sqrt{ }$ & & $\sqrt{ }$ & & $\sqrt{ }$ & & $\sqrt{ }$ & & $\sqrt{ }$ & \\
\hline 6 & $\sqrt{ }$ & & $\sqrt{ }$ & & $\sqrt{ }$ & & $\sqrt{ }$ & & $\sqrt{ }$ & \\
\hline 7 & $\sqrt{ }$ & & $\sqrt{ }$ & & $\sqrt{ }$ & & $\sqrt{ }$ & & $\sqrt{ }$ & \\
\hline 8 & $\sqrt{ }$ & & $\sqrt{ }$ & & $\sqrt{ }$ & & $\sqrt{ }$ & & $\sqrt{ }$ & \\
\hline 9 & & $\sqrt{ }$ & $\sqrt{ }$ & & $\sqrt{ }$ & & $\sqrt{ }$ & & $\sqrt{ }$ & \\
\hline 10 & $\sqrt{ }$ & & $\sqrt{ }$ & & $\sqrt{ }$ & & $\sqrt{ }$ & & $\sqrt{ }$ & \\
\hline 11 & $\sqrt{ }$ & & $\sqrt{ }$ & & $\sqrt{ }$ & & $\sqrt{ }$ & & $\sqrt{ }$ & \\
\hline 12 & $\sqrt{ }$ & & $\sqrt{ }$ & & $\sqrt{ }$ & & $\sqrt{ }$ & & $\sqrt{ }$ & \\
\hline 13 & $\sqrt{ }$ & & $\sqrt{ }$ & & $\sqrt{ }$ & & $\sqrt{ }$ & & $\sqrt{ }$ & \\
\hline 14 & $\sqrt{ }$ & & $\sqrt{ }$ & & $\sqrt{ }$ & & $\sqrt{ }$ & & $\sqrt{ }$ & \\
\hline 15 & $\sqrt{ }$ & & $\sqrt{ }$ & & $\sqrt{ }$ & & $\sqrt{ }$ & & $\sqrt{ }$ & \\
\hline 16 & $\sqrt{ }$ & & $\sqrt{ }$ & & $\sqrt{ }$ & & $\sqrt{ }$ & & $\sqrt{ }$ & \\
\hline 17 & $\sqrt{ }$ & & $\sqrt{ }$ & & & $\sqrt{ }$ & $\sqrt{ }$ & & $\sqrt{ }$ & \\
\hline 18 & $\sqrt{ }$ & & $\sqrt{ }$ & & $\sqrt{ }$ & & $\sqrt{ }$ & & $\sqrt{ }$ & \\
\hline 19 & $\sqrt{ }$ & & $\sqrt{ }$ & & $\sqrt{ }$ & & $\sqrt{ }$ & & $\sqrt{ }$ & \\
\hline 20 & $\sqrt{ }$ & & $\sqrt{ }$ & & $\sqrt{ }$ & & $\sqrt{ }$ & & $\sqrt{ }$ & \\
\hline 21 & $\sqrt{ }$ & & $\sqrt{ }$ & & $\sqrt{ }$ & & $\sqrt{ }$ & & $\sqrt{ }$ & \\
\hline 22 & $\sqrt{ }$ & & $\sqrt{ }$ & & $\sqrt{ }$ & & $\sqrt{ }$ & & $\sqrt{ }$ & \\
\hline 23 & $\sqrt{ }$ & & $\sqrt{ }$ & & $\sqrt{ }$ & & $\sqrt{ }$ & & $\sqrt{ }$ & \\
\hline 24 & $\sqrt{ }$ & & $\sqrt{ }$ & & $\sqrt{ }$ & & $\sqrt{ }$ & & $\sqrt{ }$ & \\
\hline 25 & $\sqrt{ }$ & & $\sqrt{ }$ & & $\sqrt{ }$ & & $\sqrt{ }$ & & $\sqrt{ }$ & \\
\hline
\end{tabular}


Vol.6 No.2 Tahun $2020: 64-73$

\begin{tabular}{|c|c|c|c|c|c|c|c|c|c|c|}
\hline \multirow{3}{*}{ Responden } & \multicolumn{10}{|c|}{ Pertanyaan } \\
\hline & \multicolumn{2}{|c|}{$\begin{array}{c}\text { Apakah } \\
\text { Nom.philia } \\
\text { ini mudah } \\
\text { digunakan? }\end{array}$} & \multicolumn{2}{|c|}{$\begin{array}{c}\text { Apakah } \\
\text { Nom.philia ini } \\
\text { mempunyai } \\
\text { tampilan yang } \\
\text { user friendly? }\end{array}$} & \multicolumn{2}{|c|}{$\begin{array}{c}\text { Apakah } \\
\text { Nom.philia } \\
\text { ini dapat } \\
\text { memberikan } \\
\text { rekomendasi } \\
\text { yang sesuai } \\
\text { dengan } \\
\text { harapan } \text { user } \\
\text { dalam } \\
\text { memilih } \\
\text { restoran? }\end{array}$} & \multicolumn{2}{|c|}{$\begin{array}{c}\text { Apakah } \\
\text { Nom.philia } \\
\text { dapat } \\
\text { membantu } \\
\text { user saat } \\
\text { kebingungan } \\
\text { akan makan } \\
\text { dimana hari } \\
\text { ini? }\end{array}$} & \multicolumn{2}{|c|}{$\begin{array}{c}\text { Apakah } \\
\text { Nom.philia } \\
\text { merupakan } \\
\text { suatu aplikasi } \\
\text { yang } \\
\text { sederhana dan } \\
\text { berguna bagi } \\
\text { user? }\end{array}$} \\
\hline & $\mathrm{Ya}$ & Tidak & $\mathrm{Ya}$ & Tidak & $\mathrm{Ya}$ & Tidak & $\mathrm{Ya}$ & Tidak & $\mathrm{Ya}$ & Tidak \\
\hline 26 & $\sqrt{ }$ & & $\sqrt{ }$ & & $\sqrt{ }$ & & $\sqrt{ }$ & & $\sqrt{ }$ & \\
\hline 27 & & $\sqrt{ }$ & $\sqrt{ }$ & & $\sqrt{ }$ & & $\sqrt{ }$ & & $\sqrt{ }$ & \\
\hline 28 & $\sqrt{ }$ & & $\sqrt{ }$ & & $\sqrt{ }$ & & $\sqrt{ }$ & & $\sqrt{ }$ & \\
\hline 29 & $\sqrt{ }$ & & $\sqrt{ }$ & & $\sqrt{ }$ & & $\sqrt{ }$ & & $\sqrt{ }$ & \\
\hline 30 & $\sqrt{ }$ & & $\sqrt{ }$ & & & $\sqrt{ }$ & $\sqrt{ }$ & & $\sqrt{ }$ & \\
\hline Total & 28 & 2 & 30 & $\mathbf{0}$ & 27 & 3 & 30 & $\mathbf{0}$ & 30 & $\mathbf{0}$ \\
\hline Persentase & $93 \%$ & $7 \%$ & $100 \%$ & $0 \%$ & $90 \%$ & $10 \%$ & $100 \%$ & $0 \%$ & $100 \%$ & $0 \%$ \\
\hline
\end{tabular}

Setelah mendapatkan angka-angka berupa jumlah total dan presentase dari masingmasing pertanyaan, maka diberikan penjelasan mengenai hasil pengujian tersebut. Pengujian ini dilakukan dari hasil responden yang telah menggunakan aplikasi Nom.Philia dan dari penelitian terdahulu belum ada yang menjelaskan seperti ini karena fokusnya hanya pembuatan suatu Sistem Pendukung Keputusan saja. Dalam penelitian ini diberikan penjelasan mengenai pengujian aplikasi kepada user. Penjelasannya adalah sebagai berikut:

a. Apakah Nom.philia ini mudah digunakan? Sebanyak 93\% responden menjawab Ya dan 7\% menjawab Tidak yang berarti bahwa sebagian besar responden merasa bahwa Nom.Philia mudah digunakan, yaitu berpendapat bahwa aplikasi ini sangat simple dari segi tampilan sehingga mudah dan cepat untuk mendapatkan hasilnya dan juga letak button yang ditampilkan juga mudah ditemukan. Beberapa responden menjawab Tidak karena ada beberapa responden yang terlewat mengisi pertanyaan-pertanyaannya karena baris antar pertanyaan terlalu mepet, kemudian ada pula yang berpendapat bahwa form pertanyaan terlalu banyak keluar sehingga bingung yang mana letak buttonnya.

b. Apakah Nom.philia ini mempunyai tampilan yang user friendly? Sebanyak 100\% responden menjawab Ya yang berarti bahwa semua responden merasa bahwa Nom.Philia memang mempunyai tampilan yang user friendly. Responden-responden tersebut berpendapat bahwa tampilan menu dan button sangat mudah ditemukan dan semua fungsionalitas berjalan sesuai fungsinya. Selain itu, aplikasi ini juga mempunyai alur logika yang simple dan tidak ribet saat mengoperasikannya.

c. Apakah Nom.philia ini dapat memberikan rekomendasi yang sesuai dengan harapan user dalam memilih restoran? Sebanyak 90\% responden menjawab Ya dan 10\% menjawab Tidak yang berarti bahwa sebagian besar responden merasa bahwa Nom.Philia dapat memberikan rekomendasi yang sesuai dengan harapan user dalam memilih restoran, yaitu berpendapat bahwa responden tidak ada kendala saat mendapatkan hasil dari restoran yang telah dipilih sesuai keinginan para responden tersebut dan memang apa yang sedang responden inginkan untuk dimakan, memang sesuai dengan jenis restoran yang ditampilkan sehingga responden tinggal memilih saja restoran mana yang akan didatanginya. Sedangkan ada $10 \%$ yang menjawab tidak sesuai, hal ini dikarenakan keinginan responden tidak ada diantara 3 jenis restoran yang dibuat dalam aplikasi ini (restoran Indonesia, fast food, dan nongkrong) sehingga yang muncul adalah suatu message box yang berisi kalimat: Maaf, kami tidak dapat menemukan restoran sesuai keinginan 
Anda. Hal ini juga dapat menjadi masukan bagi peneliti, bahwa aplikasi ini dapat dikembangkan lagi untuk data pertanyaan dan jenis restoran yang akan ditampilkan sehingga akan meminimalisir munculnya message box tersebut.

d. Apakah Nom.philia dapat membantu user saat kebingungan akan makan dimana hari ini? Sebanyak 100\% responden menjawab Ya yang berarti bahwa semua responden merasa bahwa Nom.Philia memang dapat membantu user saat kebingungan akan makan dimana hari ini. Responden-responden tersebut berpendapat bahwa Nom.Philia memang sangat membantu dalam memilih restoran karena banyaknya responden yang masih sering kebingungan saat akan makan dimana yang sesuai keinginannya walaupun menurut beberapa responden, aplikasi ini memang butuh untuk dikembangkan lebih lanjut agar variasi pertanyaan dan jenis restoran dapat lebih banyak. Selain hal itu, respondenresponden sangat terbantu dengan adanya aplikasi Nom.Philia ini karena simple dan mudah digunakan apalagi karena berbasis Android.

e. Apakah Nom.philia merupakan suatu aplikasi yang sederhana dan berguna bagi user? Sebanyak $100 \%$ responden menjawab Ya yang berarti bahwa semua responden merasa bahwa Nom.Philia memang merupakan suatu aplikasi yang sederhana dan berguna bagi user. Hal tersebut juga didukung dengan pertanyaan-pertanyaan lain yang memang menunjukkan bahwa Nom.Philia ini memang berguna dengan menampilkan konsep dan tampilan yang sederhana sehingga dapat dimengerti dengan mudah pula oleh para responden yang menggunakannya.

\section{SIMPULAN DAN SARAN}

Berdasarkan penelitian yang sudah dilakukan, simpulan yang didapatkan adalah telah berhasil terbangunnya Sistem Pendukung Keputusan Pemilihan Restoran Nom.Philia di Kota Palembang dengan menggunakan bahasa pemrograman Visual Basic. Selain itu, hasil pengujian blackbox sudah semua sesuai dan valid dengan apa yang ditampilkan di sistem dan juga hasil pengujian ke responden/user, sebanyak 100\% memilih Jawaban Ya untuk pertanyaan mengenai tampilan aplikasi yang user friendly, Nom.philia dapat membantu user saat kebingungan akan makan dimana hari ini, dan aplikasi yang sederhana dan berguna bagi user. Sedangkan terdapat 93\% responden menjawab Ya mengenai pertanyaan kemudahan dalam penggunaan Nom.Philia dan $90 \%$ responden menjawab Ya mengenai pertanyaan megenai kesesuaian rekomendasi yang ditampilkan sistem dengan harapan user dalam memilih restoran. Dari hasil tersebut, juga didapatkan bahwa sistem ini mudah digunakan, mempunyai tampilan yang user friendly, membantu user dalam kebingungannya, berguna untuk user, dan dapat menampilkan rekomendasi yang sesuai dengan harapan user.

\section{DAFTAR PUSTAKA}

[1] A. W. Marsum, Restoran dan Segala Permasalahannya, Empat. Yogyakarta: Andi, 2005.

[2] Badudu, Kamus Besar Bahasa Indonesia. Jakarta: Balai Pustaka, 2001.

[3] R. H. Sprague and H. J. Watson, Decision Support Systems: Putting Theory IntoPractice. Englewood Clifts: Prentice Hall, 1993.

[4] R. S. Pressman, Rekayasa Perangkat Lunak. Pendekatan Praktisi Buku I. Yogyakarta: Andi, 2015.

[5] J. A. Black and D. J. Champion, Metode \& masalah Penelitian Sosial. Bandung: Rafika Aditama, 2009.

[6] E. H. Atmoko, Program Akuntansi beserta Manajemen Aset Menggunakan VB dan SQL Server. Jakarta: PT. Elex Media Komputindo, 2015.

[7] Hamdani, "Sistem Pendukung Keputusan Pemilihan Restoran di Kota Bengkulu dengan Metode Simple Additive Weighting Berbasis Sistem Operasi Android," J. Inform. Mulawarman, vol. 5, no. 1, pp. 19-26, 2010. 
Jurnal Teknologi dan Manajemen Informatika (JTMI)

Vol.6 No.2 Tahun 2020 : 64-73

[8] Fuspita and Vera, "Sistem Pendukung Keputusan Wisata Kuliner dengan Visualisasi Geografi di Yogyakarta,” J. Rekursif, vol. 2, no. 1, pp. 45-52, 2014. 